\title{
Depressive symptoms among undergraduate Medical students: Study from a Medical college in Kolkata, India.
}

\author{
Dr Jhuma Sarkar ${ }^{1,}$ Dr Prajjal SenGupta ${ }^{2,}$ Dr Nirmalya Manna ${ }^{1,}$ Dr Asit Baran \\ Saren $^{3,}$ Dr Sita Chattopadhyay ${ }^{4}$ Dr Malay Mundle ${ }^{1}$ \\ ${ }^{1}$ Department of Community Medicine, Medical College, Kolkata, India \\ ${ }^{2}$ Department of Community Medicine, N.R.S Medical College, Kolkata, India \\ ${ }^{3}$ Department of Community Medicine, B.S Medical College, Bankura, India \\ ${ }^{4}$ Department of Community Medicine, I.P.G.M.E\&R, Kolkata, India
}

\begin{abstract}
Psychological Morbidities among medical undergraduates are quite common at various stages of their training, which vary depending on academic pressures, different socio-demographic factors and the scale of measurement. Impaired mental health among students may adversely influence their academic performances, play a role in alcohol and substance use and place them at increased risk of suicidal attempts. A cross-sectional questionnaire based study was undertaken among undergraduate medical students of different batches in a Medical College in Kolkata, India using BDI II scale to assess the proportion of students had depressive symptoms along with relation of some socio-demographic factors and methods to cope with. Males and hostelites were more. Total $41.1 \%$ had probable depression among which $15 \%$ had Mild and $26.1 \%$ had ModSevere depression. Lower proportion of depression found among $3^{\text {rd }}$.semester batch (21.6\%) than their senior batches. Depression was more among males, hostelites, students coming from higher income category. As cope up strategies, $24.4 \%$ adopted substance abuse, $6.7 \%$ attempted self mutilation which even increased to $17 \%$ for Mod-Severe depression. Screening for psychological well being of the medical students during training on regular basis along with appropriate intervention is the need of the hour.
\end{abstract}

Keywords: Beck Depression Inventory, Depression, Medical Undergraduates, Semester.

\section{Introduction}

Training in Medical Colleges is intended to prepare graduates for a personally rewarding, career promoting and socially meaningful health care provider. During medical training students are subjected to different kinds of stressors such as burden of vast academic pressure with an obligation to succeed, an uncertain future, difficulties of integrating into the system along with emotional, social, physical and family problems. These stressors often exert an inadvertent negative effect with catastrophic consequences on students' academic performances, physical health and psychological well being with a high frequency of depression, anxiety, stress and even attrition from medical course. Psychological distress among students' also reduces their self-esteem, quality of life and the quality of care they provide to patients with decreased empathy. They may engage in potentially harmful methods of coping strategy from stress such as tobacco, alcohol and other substance abuse. Medical students have a higher risk of suicidal ideation and suicide than age matched peers and general population. ${ }^{1-9}$ Worldwide, the three main causes of years lost because of disability (YLDs) for 10-24 years old were neuropsychiatric disorders (45\%), unintentional injuries(12\%) and infection and parasitic diseases(10\%). Depression among medical students is an issue of concern worldwide for nearly half a century. It is very important to detect early symptoms of depression with appropriate intervention so that ill effects of depression could not hamper one's education and career, thereby protecting valuable future human resource. Prevalence of depression among medical students varies depending on age, gender, year of training, place of staying during training, ethnicity, geographical area, parents' socio-economic status and the scale used to measure depression. ${ }^{3,6,9,10}$

With these perspectives, we conducted the present study with the following objectives:

1) To assess depressive symptoms among M.B.B.S students of different semesters using BDI scale alongwith relation of some socio-demographic factors with presence of depression.

2) To find out the coping strategies of depression among the study population.

\section{Methodology}

A cross-sectional questionnaire based study was carried out in the month of November, 2012 in a Government Medical college in Kolkata, West Bengal, India. Data were collected on a particular day involving students of different batches present on that day in different places in the college campus like canteen, library, hostels and classrooms. The undergraduate M.B.B.S course under West Bengal University of Health Science is 
a four and half year course with nine semester batches and one year compulsory rotatory Internship period. Semester batches of odd numbers $\left(3^{\text {rd }}, 5^{\text {th }}, 7^{\text {th }}, 9^{\text {th }},\right)$ were available during the day of data collection. After briefing the purpose of the study the students were encouraged to participate in the study. Students who reported suffering from any psychological disorders were excluded. Participation was voluntary, informed verbal consent was taken from the participants and they were ensured that confidentiality and anonymity would be maintained throught the study. Total 183 students volunteered for the study. Due to incompleteness finally 180 questionnaires were analyzed. Before data collection Institutional Ethics Committee clearance and permission from the Head of the Institution were taken. This study was in accordance with Helsinki declaration. Data were collected using Beck Depression Inventory II(BDI II), which is a well established reliable questionnaire used to screen for depression and has been validated in non psychotic patients in different studies. ${ }^{1,6,11,12,13}$ Beck Depression Inventory (BDI, BDI II) created by Aaron T.Beck, is a 21-question multiple choice self-report inventory. It is a subjective scale used for screening purpose which has to be further evaluated to confirm the diagnoses. In its current version the questionnaire is designed for individuals aged 13 and over, and is composed of items relating to symptoms of depression in last two weeks such as hopelessness and irritability, cognitions such as guilt or feelings of being punished, as well as physical symptoms such as fatigue and weight loss. Beck developed a triad of negative cognitions about the world, the future and the self which play a major role in depression. Each question has a set of at least four possible answer choices, ranging in intensity on a scale value of 0 to 3 and total score being 63.Higher total score indicates more severe depressive symptoms. The cut-offs we used were 0-13 no depression, 14-19 mild depression, $\geq 20$ moderate-severe depression.BDI II is positively correlated with the Hamilton Depression Rating scale and highly reliable. ${ }^{14,15}$ The questionnaire also included some socio-demographic variables such as gender, place of staying, fathers' education, occupation, income ,position among sibling, relation with parents, friends and coping strategies. Substance Abuse was considered if the students used any one of these substances in last 2 weeks like tobacco, alcohol, gutkha, sedatives, hypnotics, illicit drugs. Data were analyzed using EpiInfo version 3.5.1 by descriptive statistics and $\chi^{2}$ when needed. P value $<0.05$ was considered as significant.

\section{Results}

Background characteristics of the study population has been depicted in Table 1.Among the interviewed students proportion of male was more (54.4\%) which was also true for different semester batches except $9^{\text {th }}$ semester where proportion of female was more (55.3\%).Majority of the study population $(72.2 \%)$ were hostelites. For the $7^{\text {th }}$ Semester batch, proportion of Day Scholar was more (34.9\%) compared to other batches. In our study we have found $58.9 \%$ had no depression (score $0-13$ ), $15.0 \%$ had probable mild depression $(14-19)$ and $26.1 \%$ had probable moderate-severe depression $(\geq 20)$ using BDI II scale. For no depression $3^{\text {rd }}$ semester students were more $(72.8 \%)$ followed by $7^{\text {th }}$ semester $(58.1 \%)$. When the level of depression was mild, $7^{\text {th }}$ semester were more $(23.2 \%)$ followed by $9^{\text {th }}$ semester $(15.8 \%)$. More proportion of $5^{\text {th }}$ semester students $(39.0 \%)$ had moderate-severe level of depression followed by $9^{\text {th }}$ semester $(31.6 \%)$. Among males, $5^{\text {th }}$ semester hostelite had higher mean BDI score $(19.7 \pm 8.9)$ and $3^{\text {rd }}$ semester day scholar (had lowest mean score $(12.38 \pm 5.2)$ which was also lowest among all interviewed students. Among females highest mean score found in female day scholar of $7^{\text {th }}$ semester students $(27 \pm 16.9)$ which was also highest score among all interviewed students and lowest mean was found in $7^{\text {th }}$ semester hostelites $(12.5 \pm 6.3)$. Table 2 showed that $13.3 \%$ students treat their father like ATM, for students who had no depression this was $5.6 \%$ which gradually increased to $11.1 \%$ for mildly depressed students and $31.9 \%$ when the depression level was moderate-severe depression. More proportion of respondents were friendly \& confidant with their mother $(68.9 \%)$ than with their father (57.8\%).Apprehension of telling secret to father was less (7.5\%) than mother (14.1\%) for not depressed students. But this aspect was more towards father in case of mild depression $(22.2 \%$ vs $11.1 \%)$ and also moderate-severe depression (10.6\% vs 4.2\%). More proportion of mild depressed students (37.0\%) was neutral with their father and in moderate-severe level depression $40.4 \%$ students were neutral towards their mother. Relation of the respondents with their friends was very cordial among majority $(70.0 \%)$ which was also true for all levels of depression. Nearly two fifth $(41.2 \%)$ students do not have any boylgirl friend, which was more (51.8\%) in mild depressed category. Very highly committed to their boylgirl friend was the response among $33.3 \%$ mild depressed students. Among moderate-severely depressed students $23.4 \%$ had break-ups before with their boylgirl friends. Table 3 showed that for 3rd semester students, proportion of depressed students was less (21.6\%) compared to other senior batches and their not depressed counterpart was more(39.6\%).As the year of study increases proportion of depressed students were more than not-depressed students $\left(5^{\text {th }}\right.$ semester-29.8\% vs $17.9 \%, 7^{\text {th }}$ semester- $24.3 \%$ vs $23.6 \%, 9^{\text {th }}$ semester $24.3 \%$ vs $18.9 \%$ consecutively). Though this relation was not statistically significant $(\mathrm{p}=0.05)$. More proportion of male was depressed $(56.7 \%)$ than their female counterpart (43.3\%),but this findings was not significant. Depressed students were nearly double among hostelites $(66.2 \%)$ than day-scholars (33.8\%), but this was not statistically significant. No significant relation between presence of depression and fathers' literacy level, occupation, and position among sibling was found. 
When the fathers' income was upto Rs.9999 proportion of depressed students was less than not depressed (39.2\% vs 52.8\%). When the income of the father increased, the proportion of depressed students also increased than not depressed counterpart (Rs.10000-19999-36.5\% vs 34.9\%, $\geq$ Rs.20000-24.3\% vs $12.3 \%$ consecutively),but it was not significant. Table 4 showed that more proportion of students confide in to their friends followed by parents as a coping strategies which was also true for any level of depression. Among the surveyed students $6.7 \%$ attempted self mutilation, this proportion increased as the level of depression increased (mild-11.1\%,moderate-severe-17\%).Most commonly adopted strategy for relief when depressed, was falling in substance abuse $(24.4 \%)$ which was $46.8 \%$ for moderate-severely depressed patients. Speaking to friends (48.8\%) followed by parents (43.3\%) were other strategies. Only 5.5\% students visited counselor but $14.3 \%$ mod-severely depressed students visited counselor. Only $2.8 \%$ students spoke to teachers, which was $8.5 \%$ for mod-severely depressed students.

\section{Discussion}

Psychological well being is important for medical students, for the patients they met and for their future medical practice. Current education process in medical training exposes their students several types of stressors, some are exogenous such as adaptation to medical curriculum, vastness etc. and some are endogenous like gender, personality traits etc. This study presents the report of 180 undergraduate medical students of a Medical College in Kolkata, West Bengal, India where this type of study was not done in the recent past. We have used the reliable and valid depression screening tool, BDI II. The overall depression reported by our respondents was $41.1 \%$ of which $15.0 \%$ had mild and $26.1 \%$ had moderate-severe depression. Using same BDI scale, findings of the study done by Dr Singh \& others (49.1\%) in a Medical College in Northern India and another study in India by Ganesh S Kumar \& others $(71.25 \%)$ in Mangalore, Karnataka found higher proportion of depressive symptoms among medical undergraduates. ${ }^{6,13}$ This difference may be due to different study area, different cutoffs used to analyze the results. Other studies in different parts of the world also showed wide range of variation of depression among medical trainees, $2.2 \%$-upto $85 \%$ of the students. Reasons are different geographical regions, different sample sizes with varied demographic characteristics, scales used to assess depression and cutoffs used were also different and different medical curricula in these countries. In our study we found that as the depression level increases social relations of the respondents with their parents and friends also worsens which emphasizes that during medical training, medical educators should also pay attention to develop some strategies for reduction of stress of their students. Parents should also be careful that they do not pressurize their sons \& daughters for their high expectations. This study showed more proportion of males had depression than females, but the highest mean depression score found among females and lowest mean depression score found among males. This difference in proportion of depression among respondent according to gender in our study was not statistically significant. Our findings was in contrast to the findings of other studies where they found rates of depression among women two times higher as shown by Deborah Goebert \& others in Multischool study in Hawaii, ${ }^{3}$ significantly more than their male counterpart as shown by other studies. ${ }^{1,3,16,17}$ Similar to our study findings Ganesh S Kumar \& others in Mangalore, India, also found proportion of male depressed students were more and it was not statistically significant. ${ }^{13}$ Other studies also showed that male and female medical students did not differ in the degree of depressed mood. ${ }^{9,18}$ Male students in our study had more depressive symptoms, which may be due to their more competitiveness and future planning, less adjustment in the hostel atmosphere as we found that male hostelites had more mean BDI score than day scholars. This study showed that hostelites had more depressive symptoms, reason of which might be due to the quality of food in the hostels, lack of entertainment, feeling of loneliness. Though we had not searched for that but these were some of the reasons shown by the study done by Chandrashekhar T Sreeramareddy \& others in their study in Nepal Medical schools. ${ }^{2}$ This study showed that proportion of depressed students was less in the $3^{\text {rd }}$. semester batch than senior batches, consistent to the findings shown by Hamza Mohammad Abdul ghani \& others in their study in Saudi Arabia(highly significant) ${ }^{19}$ and also other studies. ${ }^{2,13}$ Contrary to our study findings the study by Ajit Singh \& others in Northern India found students of junior years of study had more proportion of depressive symptoms ${ }^{6}$ and the same findings was also shown by other study. ${ }^{4}$ Another study done by G.M.Koochaki in Eastern Mediterranean region found there were no significant differences between years of study and prevalence of depression. ${ }^{20}$ More depressive symptoms among higher semester batches in our study might be due to the information overload, increasing examination load, increasing future planning pressure to become a successful doctor with less time to spend in recreational activities. We found in this study that students coming from higher income groups had more proportion of depressive symptoms, reasons of which might be due to more expectation and pressure from their parents resulted in increased stress among these students. This study showed that friends followed by parents were the persons to whom the respondents confide in when depressed, whereas few proportions (2.8\%) spoke to their teachers and only 5.5\% visited a counselor. As it is well established that Medical Training is a stressful period, teachers must come forward to be friendlier with their students, interact with the students how to deal with stressors and encourage them to seek counseling when needed. Similar to 
other studies, our study also found nearly one-fourth respondents adopted substance abuse as one of the method to cope with depression, which even increased to nearly half of the students for severely depressed category. This findings were in accordance with different studies- a meta analyses of 248 articles by Dyrbye \& others ${ }^{1}$ and also by other studies. ${ }^{8,13}$ This study also showed that, ideation of self-mutilation was another method to cope-up, which even increased with increase in BDI score and our findings was more as reported by Thomas L. Schwenk $\&$ others. ${ }^{8}$ The mental health status of the students we assessed showed a worrying picture. After this study, those whom we found to have probable depression were counseled and encouraged to meet counselor \& psychologist.

Our study was a cross-sectional study, so cause and effect relationship of psychological morbidity with other factors could not be established. The scale we screened for depression was a self reporting subjective scale; therefore the scores can be easily exaggerated or minimized by the person completing them. Therefore, it can be evaluated by further studies in depth by quantitative \& qualitative methods.

\section{Conclusion}

Our findings emphasize the importance of screening for depression of medical students during training on a regular basis for early detection and taking appropriate intervention like group counseling, stress management training etc. to protect this valuable future human resource.

\section{TABLES}

Table 1 : Distribution of medical students of different batches according to their gender, residence and BDI score $\quad(\mathrm{n}=180)$

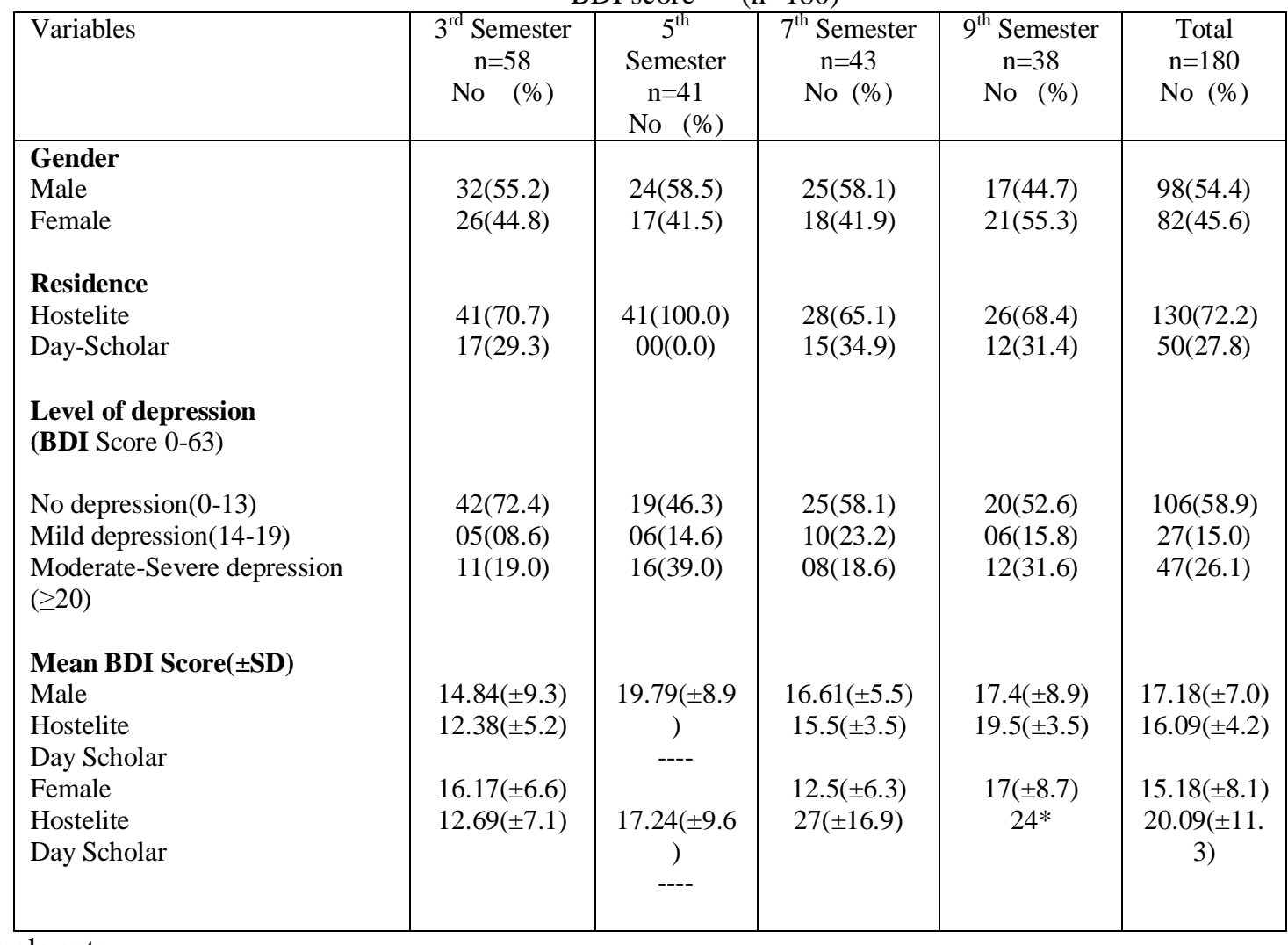

*single entry

Table 2: Level of depression of respondents and their relation with parents, friends and having boylgirl friends.

\begin{tabular}{|l|c|c|c|c|}
\hline Variables & $\begin{array}{c}\text { No depression } \\
\text { (Score 0-13) } \\
\mathrm{n}=106\end{array}$ & $\begin{array}{c}\text { Mild } \\
\text { (Score 14-19) } \\
\mathrm{n}=27 \\
\text { No. }(\%)\end{array}$ & $\begin{array}{c}\text { Mod.-Severe } \\
\text { depression } \\
(\text { Score } \geq 20) \\
\mathrm{n}=47 \\
\text { No. }(\%)\end{array}$ & $\begin{array}{c}\text { Total } \\
\text { (Score } 0-63)\end{array}$ \\
\hline $\begin{array}{l}\text { Nolation with parents } \\
\text { Treat like ATM }\end{array}$ & & & & \\
$\begin{array}{l}\text { Father } \\
\text { Mother }\end{array}$ & $06(5.6)$ & $03(11.1)$ & $15(31.9)$ & $24(13.3)$ \\
\hline
\end{tabular}


Depressive symptoms among undergraduate Medical students: Study from a Medical college in

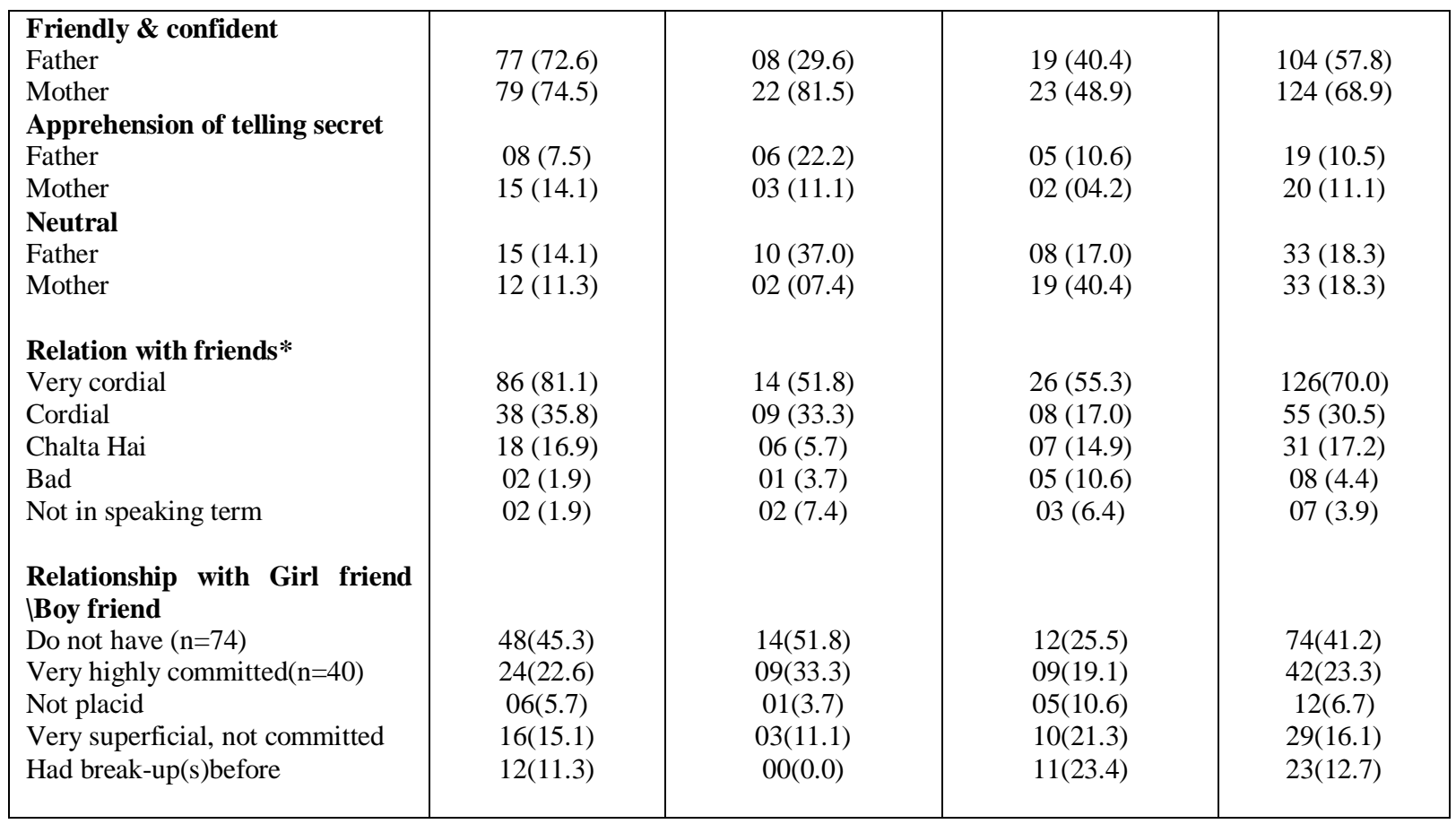

*overlapping present

Table 3: Study population according to their presence of depression and relation of some factors.

\begin{tabular}{|c|c|c|c|c|c|}
\hline Variables & $\begin{array}{c}\text { Not depressed } \\
\text { Score }(0-13) \\
n=106 \\
\text { no. }(\%)\end{array}$ & $\begin{array}{c}\text { Depressed } \\
\text { Score }(14-63) \\
\mathrm{n}=74 \\
\text { no. }(\%)\end{array}$ & $\square^{2}$ & df & $\mathbf{p}$ \\
\hline \multicolumn{6}{|l|}{ Semester Batch } \\
\hline Third & $42(39.6)$ & $16(21.6)$ & & & \\
\hline Fifth & $19(17.9)$ & $22(29.8)$ & 7.67 & 3 & .05 \\
\hline Seventh & $25(23.6)$ & $18(24.3)$ & & & \\
\hline Nineth & $20(18.9)$ & $18(24.3)$ & & & \\
\hline \multicolumn{6}{|l|}{ Gender } \\
\hline Male & $56(52.8)$ & $42(56.7)$ & .27 & 1 & .27 \\
\hline Female & $50(47.2)$ & $32(43.3)$ & & & \\
\hline \multicolumn{6}{|l|}{ Residence } \\
\hline Hostelite & $81(76.4)$ & $49(66.2)$ & 2.26 & 1 & .13 \\
\hline Day-Scholar & $25(23.6)$ & $25(33.8)$ & & & \\
\hline \multicolumn{6}{|l|}{ Position among sibling } \\
\hline Eldest & $34(32.1)$ & $22(29.8)$ & & & \\
\hline Intermediate & $21(19.8)$ & 17(22.9) & 2.19 & 3 & .53 \\
\hline Youngest & $20(18.9)$ & $19(25.7)$ & & & \\
\hline Only child & $31(29.2)$ & $16(21.6)$ & & & \\
\hline \multicolumn{6}{|l|}{ Fathers' Education } \\
\hline Upto Secondary level & $12(11.7)$ & $16(21.6)$ & 3.52 & 1 & .06 \\
\hline Above Secondary level & $94(88.7)$ & $58(78.4)$ & & & \\
\hline \multicolumn{6}{|l|}{ Fathers' Occupation } \\
\hline Professional & $43(40.6)$ & $23(31.1)$ & & & \\
\hline Executive & $27(25.5)$ & $26(35.1)$ & 3.92 & 4 & .41 \\
\hline Clerical & $09(8.5)$ & $09(12.2)$ & & & \\
\hline Semi-skilled & $07(6.5)$ & $06(8.1)$ & & & \\
\hline Skilled & $20(18.9)$ & $10(13.5)$ & & & \\
\hline \multicolumn{6}{|l|}{ Per Capita Monthly Family } \\
\hline Income in Indian Rupees & & & & & \\
\hline $0-9999$ & $56(52.8)$ & $29(39.2)$ & 5.43 & 2 & .06 \\
\hline 10000-19999 & $37(34.9)$ & $27(36.5)$ & & & \\
\hline$\geq 20000$ & $13(12.3)$ & $25(24.3)$ & & & \\
\hline
\end{tabular}


Table 4: Distribution of the students according to the level of depression and different coping strategies.

\begin{tabular}{|c|c|c|c|c|}
\hline Variables & $\begin{array}{l}\text { No depression } \\
\begin{array}{c}\text { (Score } 0-13) \\
n=106 \\
\text { No. }(\%)\end{array}\end{array}$ & $\begin{array}{c}\text { Mild } \\
\text { depression } \\
\text { (Score14- } \\
19) \\
\mathrm{n}=27 \\
\text { No. }(\%)\end{array}$ & $\begin{array}{c}\text { Mod.-Severe } \\
\text { depression } \\
\text { (Score } \geq 20) \\
n=47 \\
\text { No. }(\%)\end{array}$ & $\begin{array}{c}\text { Total } \\
\\
\text { (Score 0-63) } \\
\text { n=180 } \\
\text { No. }(\%)\end{array}$ \\
\hline $\begin{array}{l}\text { Person to whom confide } \\
\text { in when depressed }{ }^{*}\end{array}$ & & & & \\
\hline No one & $07(6.6)$ & 03(11.1) & $09(19.1)$ & 19(10.4) \\
\hline Parents & $46(43.4)$ & 08(29.6) & 11(23.4) & $65(36.1)$ \\
\hline Siblings & $16(15.1)$ & $06(22.2)$ & 07(14.9) & $29(16.1)$ \\
\hline Friend & $47(44.3)$ & $12(44.4)$ & $19(40.4)$ & $78(43.3)$ \\
\hline Boylgirl friend & $23(21.7)$ & $05(18.5)$ & $07(14.9)$ & $35(19.4)$ \\
\hline Teacher & $00(0.0)$ & 03(11.1) & $02(4.2)$ & $05(2.8)$ \\
\hline Roommate & $10(9.4)$ & $01(3.7)$ & $05(10.6)$ & $16(8.9)$ \\
\hline $\begin{array}{l}\text { Self-Mutilation attempted } \\
\text { Relief sought when depressed* }\end{array}$ & $01(0.9)$ & $03(11.1)$ & $08(17.0)$ & $12(6.7)$ \\
\hline Substance Abuse & 19(17.9) & $03(11.1)$ & $22(46.8)$ & $44(24.4)$ \\
\hline Visiting a counsellor & $03(2.8)$ & $00(0.0)$ & $07(14.9)$ & $10(5.5)$ \\
\hline Speaking to a teacher & $01(0.9)$ & $00(0.0)$ & $04(8.5)$ & $05(2.8)$ \\
\hline Speaking to a friend & $54(50.9)$ & $18(66.7)$ & $16(34.0)$ & $88(48.8)$ \\
\hline Speaking to parents & $57(53.8)$ & $11(40.7)$ & $10(21.3)$ & $78(43.3)$ \\
\hline Speaking to myself & $01(0.9)$ & $01(3.7)$ & $00(0.0)$ & $02(1.1)$ \\
\hline
\end{tabular}

*overlapping present

\section{References}

[1] Dyrbye, Liselotte N, Thomas, Matthew R., Shanafelt, Tait D. Systematic Review of Depression, Anxiety and other Indicators of Psychological Distress Among U.S. and Canadian Medical Students. Academic Medicine, April 2006;81(4):354-73.

[2] Chandrashekhar T Sreeramareddy, Pathiyil R Shankar, VS Binu, Chiranjoy Mukhopadhyay, Biswabina Ray and Ritesh G Menezes. Psychological morbidity,sources of stress and coping strategies among undergraduate medical students of Nepal. BMC Medical Education 2007;7:26.

[3] Deborah Goebert, Diane Thompson, Junji Takeshita, Cheryl Bech, Philip Bryson, Kimberly Ephgrave et al. Depressive Symptoms in Medical Students and Residents: A Multischool study. Academic Medicine,February 2009;84(2):236-41.

[4] Marjani A, Gharavi AM, Jahanshahi M, Vahidirad A, Alizadeh F. Stress among medical students of Gorgan (South East of Caspian Sea), Iran. Kathmandu Univ Med J (KUMJ). 2008 Jul-Sep;6(23):421-5.

[5] Najmeh Jafari, Amir Loghmani, Ali Montazeri. Mental health of Medical Students in Different Levels of Training. Int J Prev Med. 2012 March; 3(Suppl1): S107-S112.

[6] Ajit Singh, Amarlal, Shekhar. Prevalence of depression Among Medical Students of a Pvt Medical College:India.[ accessed online http://www.ojhas.org/issue 36/2010-4.8ht]

[7] James M Hillis, William R G Perry, Emily Y Carroll, Belinda A Hibble, Marion J Davies, Justin Yousef. Painting the picture: Australasian medical student views on wellbeing, teaching and support services. New Zealand Medical Student Journal May 201

[8] Thomas L. Schwenk, Lindsay Davis, Leslie A.WimSatt. Depression,Stigma and Suicidal Ideation in Medical Students. JAMA 2010;304(11):1181-90(doi,10.1001/jama,2010.1300).

[9] Thelma A Quince, Diana F Wood, Richard A Parker, John Benson. Prevalence and persistence of depression among undergraduate medical students: a longitudinal study at one U.K Medical School.BMJ Open 2012;00:e001519.doi:10.1136 bmjopen-2012-001519

[10] Gore F M, Bloem P J, Patton G C, Forquson J, Joseph V,Coffey C et al.Global burden of disease in young people aged 10-24 yrs.: a systematic analyses. Lancet 2011 Jun 18;377(9783):2093-102.

[11] Beck Depression Inventory from Wikipedia accessed on 29.11.12.

[12] Beck A, Steer R, Garbin M. Psychometric properties of Beck Depression Inventory:twenty five years.of evaluation. Clin Psychol Rev. 1988;8:77-100.

[13] Ganesh S Kumar, Animesh Jain, Supriya Hegde. Prevalence of depression and its associated factors using Beck Depression Inventory among students of a medical college in Karnataka. Indian Journal of Psychiatry 2012;54(3):223-26.

[14] Richter P, J Werner,A Heerlein, A Kraus, H Sauer(1998)."On the validity of the Beck Depression Inventory.A Review". Psychopathology, 31(3):160-8.

[15] Lassa L,Ayuso-Matcos JL, Vazquez-Barqeora JL, Diez-Manriquea EJ, Dowrickb CE. The use of Beck Depression Inventory to screen for depression in general population: a preliminary analyses. Journal of Affective Disorders 2006;57(1-3):261-65.

[16] Dahlin M,Joneborg N, Runeson B. Stress and depression among medical students:a cross-sectional study. Med Educ,2005 Jun;39(6):594-604.

[17] Shahida Shakh, Abdul Hameed Shaikh, Inayatullah Magsi. Stress among medical students of University of Interior Sindh. Medical Channel Oct-Dec 2010;16(4):538-40.

[18] David W Chan. Depressive symptoms and depressed mood among Chinese medical Students in Hong Kong. Comprehensive Psychiatry March-April 1991;32(2):170-80.

[19] Hamzan Mohammad Abdul ghani. Stress and depression among medical students: A Cross Sectional study at a Medical College in Saudi Arabia. Pak J Med Sci Jan;24(1):12-7.

[20] G. M. Koochaki, A. Charkazi,A.Hasanzadeh, M. Saedani, M. Qorbani, A. Marjani. Prevalence of stress among Iranian medical students: a questionnaire survey. Eastern Mediterranean Health Journal 2011;17(7):593-98. 